\title{
Investigation of Oxidation Behavior of 304L and 310S Steels with Potential Application in Supercritical Water-cooled Nuclear Reactors
}

\author{
FLORENTINA GALAN ${ }^{1}$, MARIAN CATALIN DUCU ${ }^{1}$, MANUELA FULGER ${ }^{2}$, \\ DENIS AURELIAN NEGREA ${ }^{1 *}$ \\ ${ }^{1}$ University of Pitesti, CRC\&D-Auto, 11 Doaga, 110440, Pitesti, Romania \\ ${ }^{2}$ Institute for Nuclear Research Pitesti, POB 78, 1 Campului Str., 115400, Mioveni, Romania
}

\begin{abstract}
Selecting proper candidate materials is one key issue for the development of the supercritical water-cooled nuclear reactor (SCWR). Designing or choosing the most fitting materials means better sustainability, economics and safety. As the supercritical water is a very aggressive corrosive media, corrosion becomes one challenging problem for the materials used in the SCWR. This paper involves the corrosion testing of two stainless steels (304L and 310S) and microstructure evaluation of samples after being exposed to supercritical water. The test parameters were set at the temperature of $550^{\circ} \mathrm{C}$ and the pressure of $25 \mathrm{MPa}$ for up to 63 days. The samples were investigated using gravimetric corrosion test, optical microscopy, scanning electron microscopy coupled with energy dispersive X-ray spectroscopy. Results showed a lower corrosion performance, in terms of weight change and surface oxide formation, for 304L due to its low chromium content. $310 \mathrm{~S}$ has excellent corrosion resistance because the chromium content is higher. The results obtained will be useful in future research of test protocol and development of alloys that could be used as reactor fuel cladding and other components in the SCWR.
\end{abstract}

Keywords: SCWR, stainless steels, oxidation, gravimetric corrosion test, SEM

\section{Introduction}

According to the latest annual reports published by the Generation IV International Forum (GIF), there is a major interest in evaluating the alloys considered candidates for all the key components of the supercritical water-cooled nuclear reactor (SCWR) projects. The purpose of researches is to study the oxidation (corrosion) behavior of the candidate metallic materials for SCWR and, at the same time, to identify the discrepancies observed in the tests.

SCWR is a high-temperature, high-pressure water-cooled reactor that operates above the thermodynamic critical point $\left(374{ }^{\circ} \mathrm{C}, 22.1 \mathrm{MPa}\right)$ of water. In general terms, the conceptual designs of SCWRs can be grouped into two main categories: pressure vessel concept and pressure tube concept. Other than specifics of the core design, these concepts have many similar features (e.g. outlet pressures and temperatures, thermal neutron spectra, steam cycle options, materials, etc.).

Under supercritical water (SCW) conditions the main concerns regarding the selection of the appropriate materials are the prevention of stress corrosion cracking and the resistance to corrosion at high temperatures and pressures, and under the neutron radiation for materials used in the reactor core. Some of the candidate materials that can be used are stainless steels and high nickel-chromium alloys. The corrosion resistance of stainless steels to oxidation in SCW environment was recently studied [1-8]. These alloys exhibit the lowest weight gains among most of the candidate alloys that are under investigation $[9,10]$. The most significant improvements in oxidation resistance are achieved by changing the inherent nature of the protective oxide scale. The high chromium content $(>20 \%)$ of the austenitic stainless steels results in an increased resistance [11]. Most reported results on austenitic stainless steels reveal that the surface oxide consists of a two- or three-layer structure.

*email: denisnegrea@yahoo.com 
The outer layer generally consists of magnetite with an inner layer that is rich in chromium and is either an iron chromium spinel or an iron chromium oxide with a hematite structure. An intermediate layer can also present between the inner layer and the base metal that appears to be supersaturated with oxygen [12-15].

Stainless steels (304L and 310S) were selected for this research, as they have the optimum balance of structural strength and corrosion resistance required for high temperature applications. The samples from each material were exposed to supercritical water to study the effects of the environment on corrosion behavior. Both stainless steels were investigated by gravimetric corrosion test, optical microscopy, scanning electron microscopy (SEM) and energy dispersive X-ray spectroscopy (EDS).

\section{Materials and Methods}

The materials selected for these comparative studies are two austenitic stainless steels, 304L and 310S. The chemical composition of the studied materials is given in Table 1.

Table 1. Chemical composition of 304L and 310S

\begin{tabular}{|l|l|l|l|l|l|l|l|l|}
\hline \multirow{2}{*}{$\begin{array}{l}\text { Stainless } \\
\text { steel }\end{array}$} & \multicolumn{6}{|l|}{ Composition (wt. \%) } \\
\cline { 2 - 9 } & $\mathrm{C}$ & $\mathrm{Si}$ & $\mathrm{Mn}$ & $\mathrm{P}$ & $\mathrm{S}$ & $\mathbf{C r}$ & $\mathbf{N i}$ & $\mathrm{Fe}$ \\
\hline $\mathbf{3 0 4 L}$ & 0.03 & 0.46 & 1.37 & 0.028 & 0.0006 & $\mathbf{1 8 . 0 7}$ & $\mathbf{8 . 1 1}$ & 71.9 \\
\hline $\mathbf{3 1 0 S}$ & 0.063 & 0.71 & 1.61 & 0.016 & 0.001 & $\mathbf{2 4 . 1 3}$ & $\mathbf{1 9 . 0 3}$ & 54.34 \\
\hline
\end{tabular}

The samples were taken as plates from each material in the delivery state from Outokumpu Stainless AB Company. Two samples of each material were prepared for each test condition. After cutting, the samples were mechanically sanded on abrasive paper of different granulations (\# 600, \# 800, \# 1200) and then with diamond paste, after which they were exposed in the acetone ultrasound for 30 minutes. After ultrasound the samples were dried and weighted using an analytical balance with an accuracy of $\pm 1 \times 10^{-}$ ${ }^{4} \mathrm{~g}$.

To simulate the supercritical environment, the experiments were performed in static one-liter autoclaves in water at $550^{\circ} \mathrm{C}$ under a pressure of $25 \mathrm{MPa}$. The exposure time was up to 63 days. The $\mathrm{pH}$ of testing solution, measured at room temperature was about 6.7. The autoclaves were opened periodically to measure weight gain of individual specimens after rinsing and drying. The autoclave solution was replaced with fresh solution after each inspection. Based on the initial weight and those obtained after autoclaving, the variation of the mass $\Delta \mathrm{W}$ in $[\mathrm{mg}]$ was calculated.

To express the corrosion rate, the variation of mass per unit area $S$ and exposure time $t$ of the coupon, $\Delta \mathrm{W} / \mathrm{S} \mathrm{t}\left(\mathrm{mg} \mathrm{dm}^{-2} \mathrm{day}^{-1}\right)$ was calculated.

After autoclaving the materials were also subjected to morphological/structural analysis. Metallographic analysis was performed using the Olympus BX51M optical microscope to highlight the grain structure. The surface morphology and composition were analyzed using scanning electron microscope FESEM (Field Emission Scanning Electron Microscopy) Hitachi SU5000 provided with energy-dispersive X-ray spectroscopy (EDS) device.

\section{Results and discussions}

Following the oxidation experiment carried out at $550^{\circ} \mathrm{C}$ up to 63 days, the weight gain values were recorded from 10 to 10 days, as are represented in the Figure 1. It is important to note that trends are based on limited experimental data because autoclave attempts require long testing periods. 


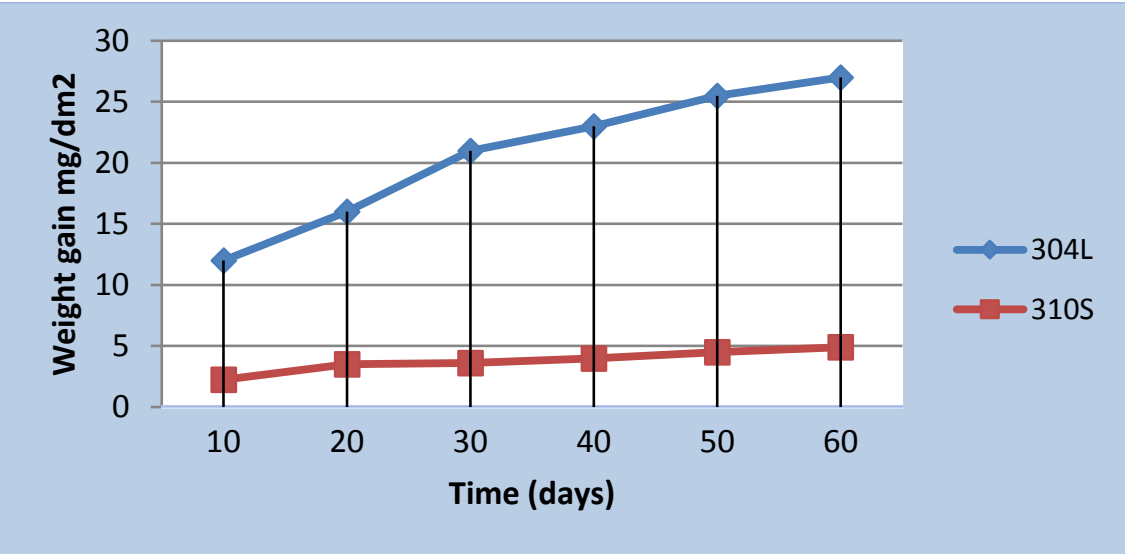

Figure 1. Weight gain data as a function of exposure time for $304 \mathrm{~L}$ and $310 \mathrm{~S}$ samples in supercritical water

Based on cumulative values in weighting the samples, the corrosion rate was calculated in time intervals from 10 to 10 days. Figure 2 shows the graph of corrosion rate in aqueous environment, under the specific conditions of the primary circuit existing in the SCWR.

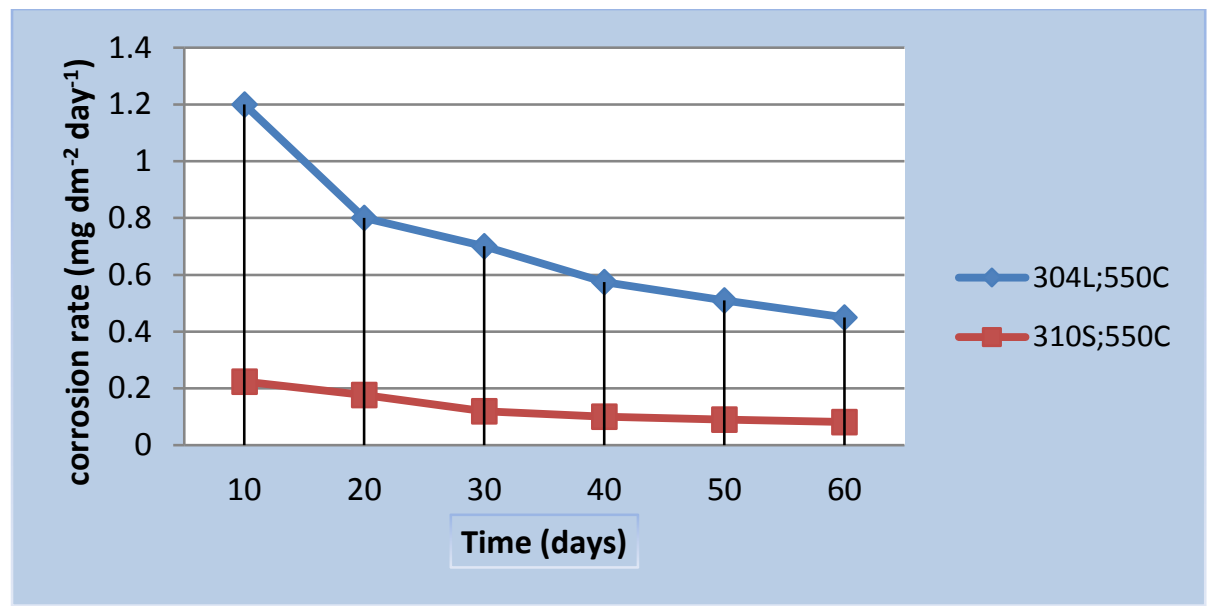

Figure 2. Corrosion rate according to exposure time in supercritical water of the $304 \mathrm{~L}$ and $310 \mathrm{~S}$ materials

Based on the results obtained from the weight gain and the corrosion rate by gravimetric analysis, it is found that the values of the weight gain represent a slight increase depending on the exposure time and the values of the corrosion rate represent a slight decrease as a function of time. From the measured data presented above, we can conclude that the lowest values of weight gain and corrosion rate belongs to the $310 \mathrm{~S}$ alloy, which makes it more suitable for the targeted purpose.

The microstructure of austenitic $304 \mathrm{~L}$ and $310 \mathrm{~S}$ was examined in reflected light, at 500x magnification, after metallographic preparation and electrochemical attack with oxalic acid. The granulated images are shown in Figure 3, which reveals the structural constituents of the samples obtained from the autoclaving tests. For this purpose, three samples from each material were selected starting from the standard sample and continuing with the tested samples for 10 and 63 days, respectively. 


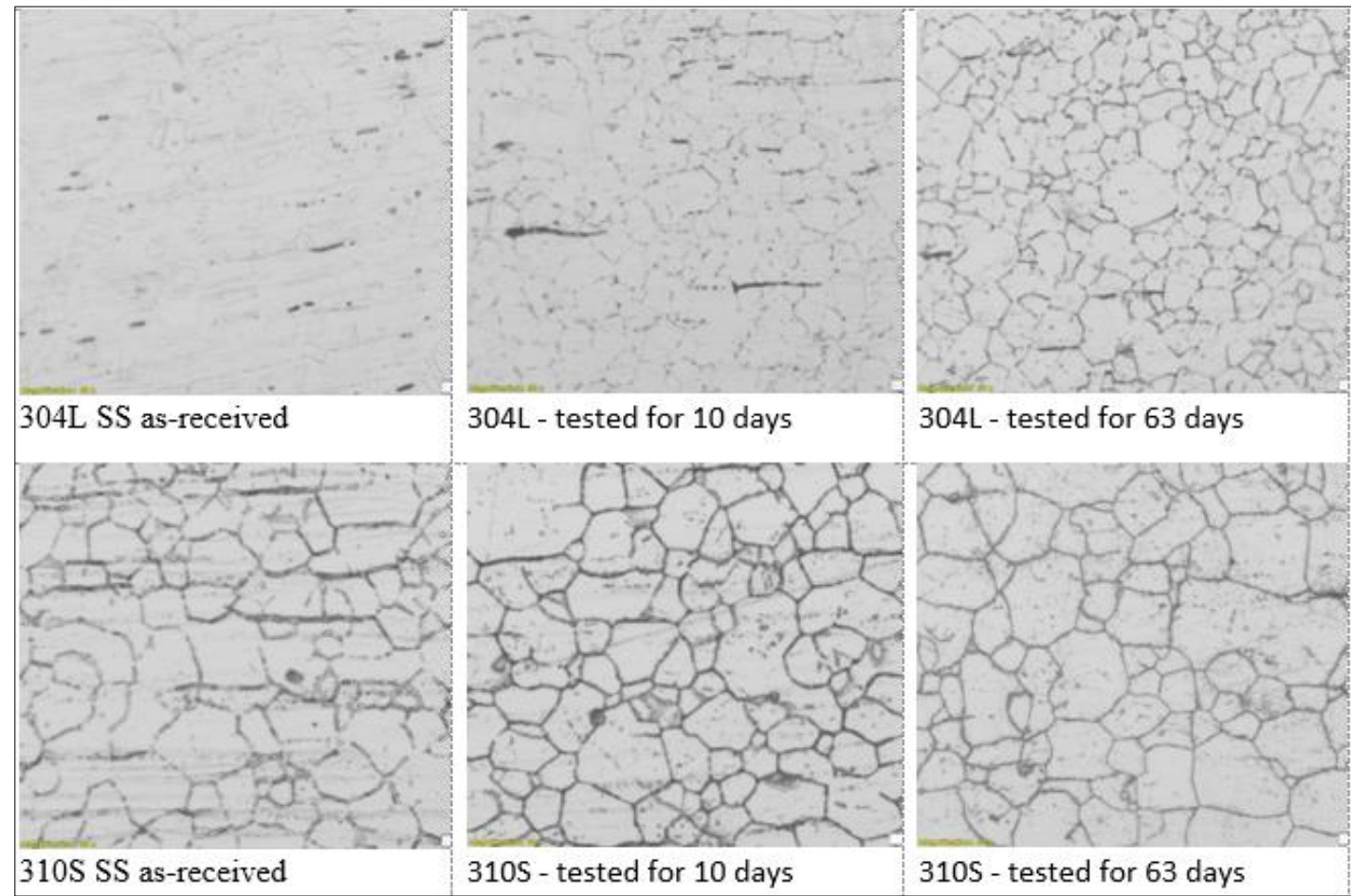

Figure 3. Grain structure $304 \mathrm{~L}$ and $310 \mathrm{~S}$ according to the test period (x 500 magnification), cross-sectional bulk images

The micrographs obtained at the 500x magnification of the standard samples (as received) reveal an austenitic structure for both steels. As the test period increases, the grain size increases. According to Hall-Petch relation, a coarse-grained microstructure could be a sign of a decrease in the strength yield for the samples exposed to the supercritical water conditions for longer time (63 days).

The topographic characteristics of oxides grown in SCW environments on 304L and 310S steels exposed at $550{ }^{\circ} \mathrm{C}$ and $25 \mathrm{MPa}$ were investigated by SEM considering a set of exposure times. Figures 4 and 5 show images of the oxides developed on the 304L and 310S samples after different exposure times.
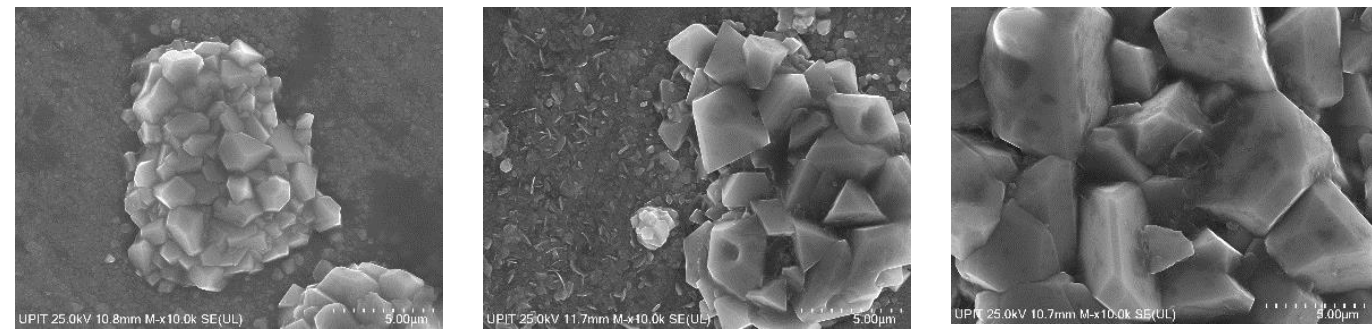

Figure 4. SEM surface images of $304 \mathrm{~L}$ exposed in $\mathrm{SCW}\left(550^{\circ} \mathrm{C}, 25 \mathrm{MPa}\right)$ for 10,20 and 63 days (x10k magnification)
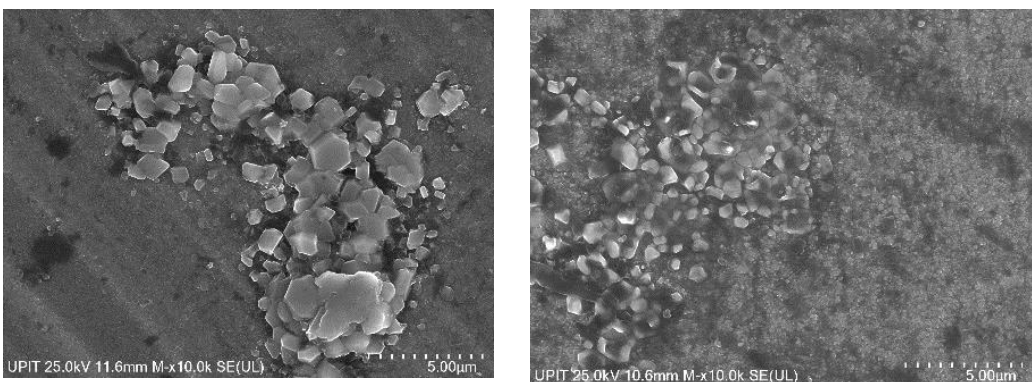

Figure 5. SEM surface images of $310 \mathrm{~S}$ exposed in SCW $\left(550^{\circ} \mathrm{C}, 25 \mathrm{MPa}\right)$ for 10 and 63 days (x10k magnification) 
The appearance and growth of corrosion product(s) (the raised islands) on the 304L after 63 days of $\mathrm{SCW}$ testing is consistent with the weight gain results obtained in the weight corrosion analysis. The process of increasing the oxide layers during exposure can be described as an initial nucleation of oxide at the selected sites, followed by a uniform growth of the oxide grains until they connect together, resulting in a compact layer. The SEM images (obtained at magnifications of $\mathrm{x} 10 \mathrm{k}$ ) indicate the presence of oxide particles with a variety of geometries and sizes, but all of which assume angular characteristics.

On the surface of $310 \mathrm{~S}$ tested in supercritical water for 10 and 63 days the corrosion products have the form of thin and elongated islands with very small crystallites. Occasionally, larger particles are present on the surface, but at a lower density. After 63 days no noticeable changes are observed compared to the 10-day sample tested in SCW. The images are consistent with the results of weight gain analysis showing a slight increasing in time, which suggests that the oxide layer developed remains thin and stable.

SEM-EDS analysis was performed on the surface of 304L exposed in SCW for 63 days. A SEM image was acquired (Figure 6.a) and three point scans have been performed in order to obtain the EDS spectra (Figure 6.b) and the local chemical elemental composition (Table 2.).

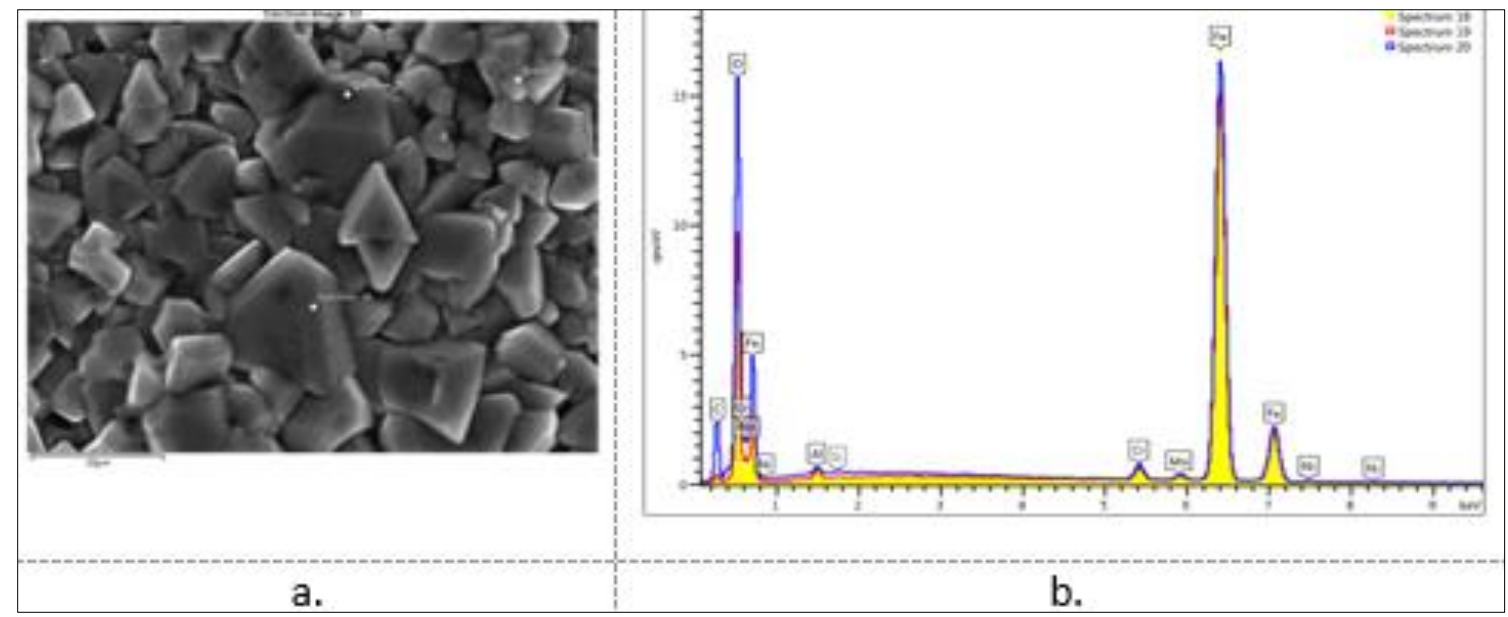

Figure 6. SEM image of 304L sample tested for 63 days with indication of selected EDS point scans (a) and the obtained EDS superimposed spectra with elemental identification (b)

Table 2. EDS elementalal analysis results from three point scans of 304L sample surface tested for 63 days

\begin{tabular}{|l|l|l|l|}
\hline \multirow{2}{*}{ Spectrum Label } & \multicolumn{3}{|c|}{ Elemental concentration (wt.\%) } \\
\cline { 2 - 4 } & Spectrum 18 & Spectrum 19 & Spectrum 20 \\
\hline $\mathrm{C}$ & 2.97 & 4.75 & 17.69 \\
\hline $\mathrm{O}$ & 22.52 & 28.68 & 37.58 \\
\hline $\mathrm{Al}$ & 1.04 & 1.05 & 0.29 \\
\hline $\mathrm{Si}$ & & 0.10 & 0.09 \\
\hline $\mathrm{Cr}$ & 1.05 & 1.21 & 0.96 \\
\hline $\mathrm{Mn}$ & 0.61 & 0.51 & 0.35 \\
\hline $\mathrm{Fe}$ & 71.66 & 63.11 & 42.84 \\
\hline $\mathrm{Ni}$ & 0.15 & 0.59 & 0.20 \\
\hline Total & 100.00 & 100.00 & 100.00 \\
\hline
\end{tabular}




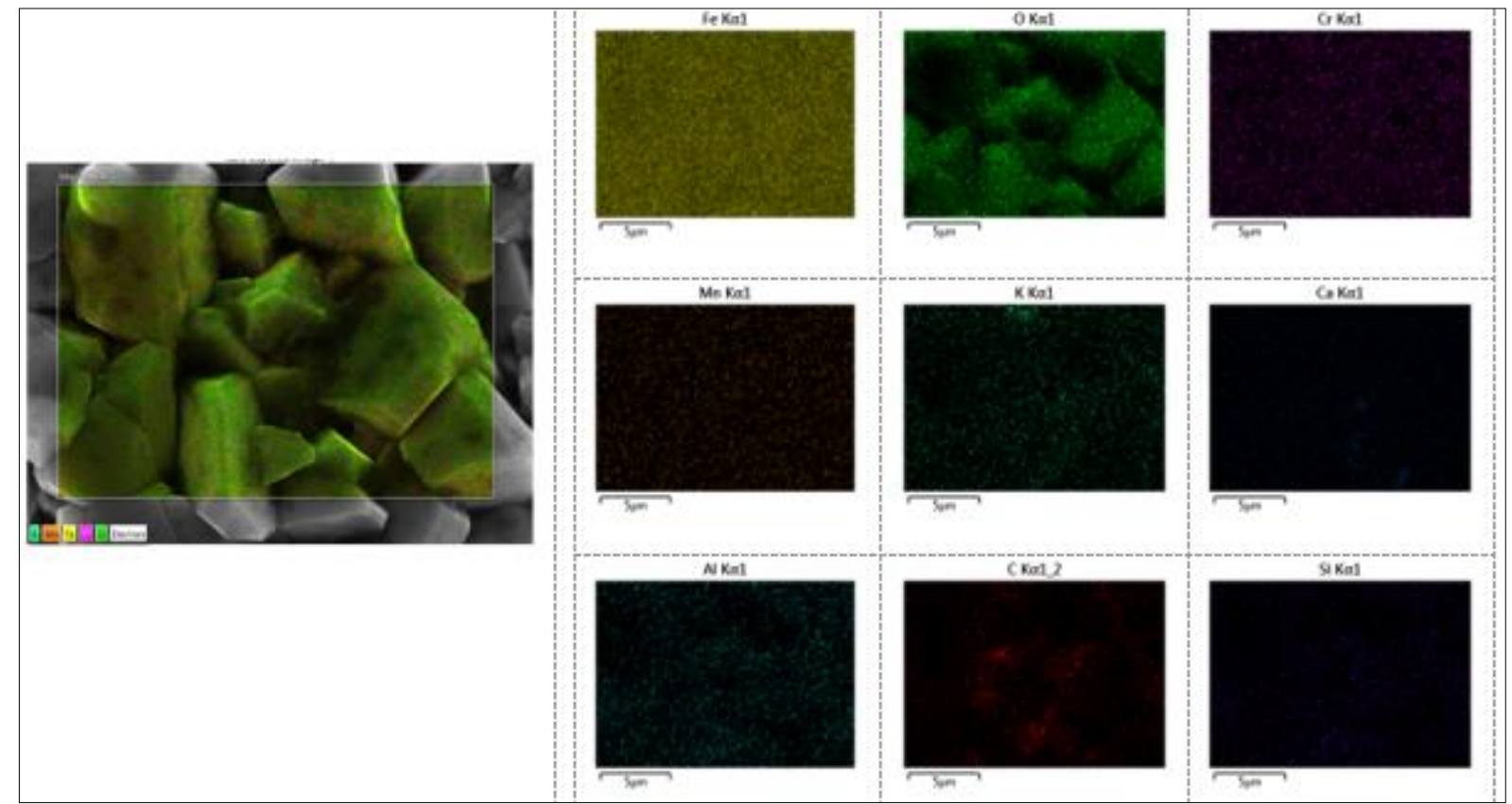

Figure 7. EDS analysis mapping results for the selected scanned area of 304L, after 63 days of SCW testing

The elevated concentration of $\mathrm{Fe}$ and $\mathrm{O}$ and lower concentration of $\mathrm{Cr}$ and $\mathrm{Ni}$ obtained on both stainless steel surfaces from the EDS analysis, might suggest the presence of iron oxide $\left(\mathrm{Fe}_{2} \mathrm{O}_{3}\right)$ as corrosion product.

Also, for 304L exposed in SCW for 63 days, an EDS mapping was performed on a selected surface area and the concentration distribution of the previous identified chemical elements was obtained (Figure 7).

Similarly the SEM and EDS analyzes were performed on 310S (Figure 8):

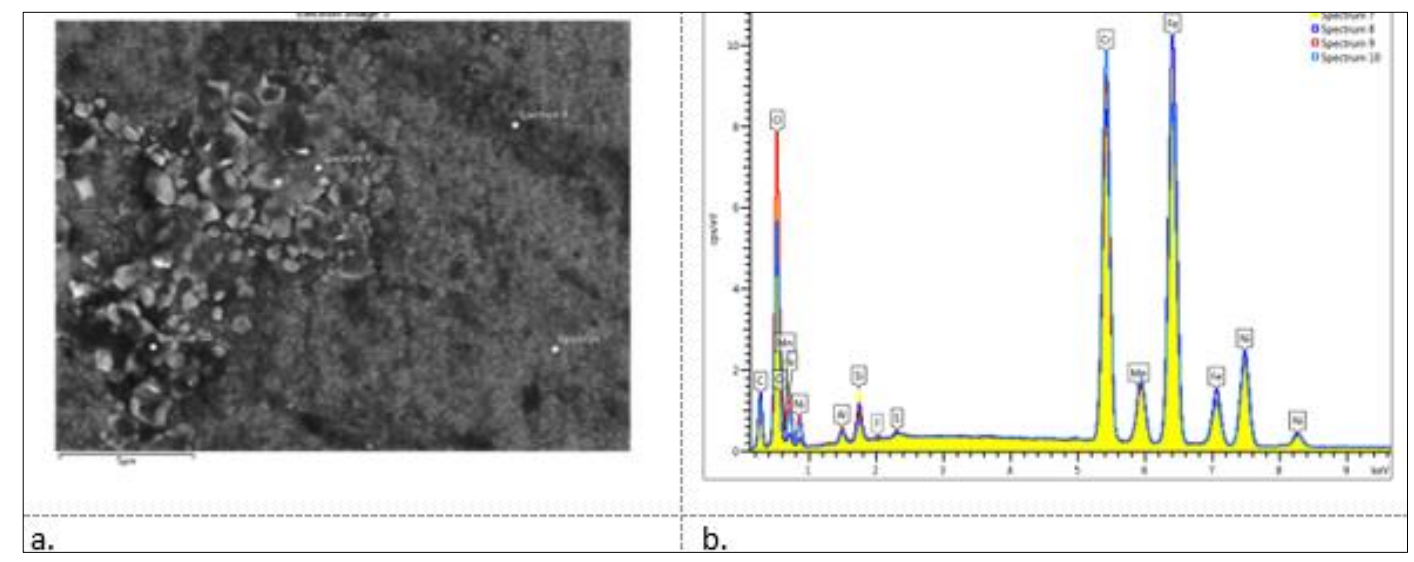

Figure 8. SEM image of 310 S sample tested for 63 days with indication of selected EDS point scans (a) and the obtained EDS superimposed spectra with elemental identification (b)

Table 3. EDS chemical elemental results from four point scans of $310 \mathrm{~S}$ sample surface tested for 63 days

\begin{tabular}{|l|l|l|l|l|}
\hline \multirow{2}{*}{ Spectrum Label } & \multicolumn{4}{|l|}{ Elemental concentration (wt.\%) } \\
\cline { 2 - 5 } & Spectrum 7 & Spectrum 8 & Spectrum 9 & Spectrum 10 \\
\hline $\mathrm{C}$ & 13.20 & 16.59 & 12.69 & 15.05 \\
\hline $\mathrm{O}$ & 21.17 & 17.73 & 24.28 & 19.07 \\
\hline $\mathrm{Al}$ & 0.77 & 0.61 & 0.68 & 0.65 \\
\hline
\end{tabular}




\begin{tabular}{|l|l|l|l|l|}
\hline $\mathrm{Si}$ & 1.87 & 1.38 & 0.97 & 0.82 \\
\hline $\mathrm{P}$ & & & 0.11 & \\
\hline $\mathrm{S}$ & 0.11 & 0.08 & 0.13 & 0.17 \\
\hline $\mathrm{Cr}$ & 19.39 & 17.95 & 20.61 & 22.73 \\
\hline $\mathrm{Mn}$ & 1.28 & 1.25 & 1.13 & 1.46 \\
\hline $\mathrm{Fe}$ & 31.22 & 33.20 & 28.71 & 29.27 \\
\hline $\mathrm{Ni}$ & 10.98 & 11.21 & 10.69 & 10.79 \\
\hline Total & 100.00 & 100.00 & 100.00 & 100.00 \\
\hline
\end{tabular}

In addition to high concentrations of iron and oxygen, small amounts of $\mathrm{Cr}$ and $\mathrm{Mn}$ are also detected in $310 \mathrm{~S}$ sample, which might be a sign of the formation on the steel surface of chromium oxide $\left(\mathrm{Cr}_{2} \mathrm{O}_{3}\right)$ or a mixed oxide $\left(\mathrm{Fe}_{2} \mathrm{CrO}_{4}\right)$.

\section{Conclusions}

Corrosion rates for 304L and 310S stainless steels exposed to supercritical water in an autoclave at $550^{\circ} \mathrm{C}$ were determined from weight gains in a time range of 63 days. Decreased values of corrosion rates from 12 to $4.5 \mathrm{mg} \mathrm{dm}^{-2} \mathrm{day}^{-1}$ for $304 \mathrm{~L}$ and from 5 to $0.1 \mathrm{mg} \mathrm{dm}^{-2} \mathrm{day}^{-1}$ for $310 \mathrm{~S}$ demonstrated that $310 \mathrm{~S}$ has a better corrosion behavior in simulated environment of SCWR nuclear reactor. SEM images on $304 \mathrm{~L}$ after being tested for 63 days in SCW show firstly separated islands until the formation of the oxide film covering the entire surface of steel, which is in accordance with the weight gain results. The process of increasing the oxide layers during exposure can be described as an initial nucleation of oxide at the selected sites, followed by a uniform growth of the oxide crystals until they connect with each other, resulting in a compact layer. The EDS analysis indicates increased concentrations of Fe and O suggesting that the oxide formed on the $304 \mathrm{~L}$ steel surface might be iron oxide $\left(\mathrm{Fe}_{2} \mathrm{O}_{3}\right)$. High values of weight gain and excessive iron oxide formation on the surface can represent a low corrosion performance of 304L steel, comparatively with $310 \mathrm{~S}$ steel.

From the SEM analyzes of the 310S it appears that after 63 days of testing in SCW simulated conditions, the oxide layer (observable at a magnification of $x 30 \mathrm{k}$ ) remained thin and stable. EDS analyzes showed increased concentrations of $\mathrm{Fe}$ and $\mathrm{O}$ (i.e. $\mathrm{Fe}_{2} \mathrm{O}_{3}$ formation) together with small amounts of $\mathrm{Cr}$ and $\mathrm{Mn}$, which might suggest the formation onto the sample surface of chromium oxide $\left(\mathrm{Cr}_{2} \mathrm{O}_{3}\right)$ or even a mixed oxide spinel type $\left(\mathrm{Fe}_{2} \mathrm{CrO}_{4}\right)$. It can be stated that $310 \mathrm{~S}$ steel has good corrosion resistance in supercritical water due to its high chromium content which lead to a more stable layer formed onto the surface.

The results obtained in this work will be useful in future research of test protocol and development of alloys that could be used as reactor fuel cladding and other components in the SCWR.

\section{References}

1. RODRIGUEZ, D., MERWIN, A., CHIDAMBARAM, D., On the oxidation of stainless steel alloy 304 in subcritical and supercritical water, Journal of Nuclear Materials, 452, no. 1-3, 2014, p. 440-445.

2. LI, W., WOO, O.T., GUZONAS, D., LI, J., HUANG, X., SANCHEZ, R., BIBBY, C.D., Effect of Pressure on the Corrosion of Materials in High Temperature Water, in: Characterization of Minerals, Metals, and Materials, CARPENTER, J.S. et al. (Eds.), Springer, Cham, 2015, p. 99-106.

3. BEHNAMIAN, Y., MOSTAFAEI, A. et al., A comparative study of oxide scales grown on stainless steel and nickel-based superalloys in ultra-high temperature supercritical water at $800^{\circ} \mathrm{C}$, Corrosion Science, 106, 2016, p. 188-207 DOI: 10.1016/j.corsci.2016.02.004

4. GONG, B., HUANG, Y., JIANG, E., ZHAO Y., LIU, W., ZHOU, Z., Effect of Oxidation Chemistry of Supercritical Water on Stress Corrosion Cracking of Austenitic Steels, J. of Nuclear Rad Sci., 2, no. 1, 2016, Article 011019

5. LI, H., CAO, Q., ZHU, Z., Oxidation behaviour of Super 304H stainless steel in supercritical water, Corrosion Engineering, Science and Technology, 53, no. 4, 2018, p. 293-301. 
6. LI, W., HUANG, X., LI, J., WOO, O.T., SANCHEZ, R., BIBBY C.D., Effect of Pressures on the Corrosion Behaviours of Materials at $625^{\circ} \mathrm{C}$, JOM - The Journal of the Minerals, Metals \& Materials Society, 69, no.2, 2017, p. 207-216.

7. SANCHEZ, R.G., HUANG, X., LIU, P., Effect of Water Density/Pressure on the Corrosion Behavior of 304 and 310 Stainless Steels, Oxid. Met., 89, 2018, p. 165-182.

8. HORVATH, A., IMRE, A.R., JAKLI, G., Investigation of Corrosion Resistance of Alloys with Potential Application in Supercritical Water-cooled Nuclear Reactors, Periodica Polytechnica Chemical Engineering, 63, no. 2, 2019, p. 328-332.

9. SUZAN, B., BINGJIE, X., XIAO,. H., SAMI, P., Oxidation Behaviour of Alloys 800H, 3033 and 304 in High-Temperature Supercritical Water, Oxidation of Metals, 89, 2018, p. 151-163.

10. ZENG, Y., GUZONAS, D., Corrosion Assessment of Candidate Materials for Fuel Cladding in Canadian SCWR, JOM, 68, no. 2, 2016, p. 475-479.

11. GUO, X., FAN, Y., GAO, W., TANG, R., CHEN, K., SHEN, Z., ZHANG, L., Corrosion resistance of candidate cladding materials for supercritical water reactor, Annals of Nuclear Energy, 127, 2019, p. 351-363.

12. FULGER, M., RADULESCU, M., LUCAN, D., DEMETRESCU, I., The corrosion kinetics of 304L stainless steel, Incoloy 800 and SA 516 carbon steel in the secondary circuit of the nuclear steam generator, Rev. Chim., 55(3), 2004, 163-168.

13.JONSSON, T., KARLSSON, S., HOOSHYAR, H., SATTARI, M., LISKE, J., SVENSSON, J.E., JOHANSSON L.G., Oxidation After Breakdown of the Chromium-Rich Scale on Stainless Steels at High Temperature: Internal Oxidation, Oxidation of Metals, 85, 2016, p. 509-536.

14. BEHNAMIAN, Y., MOSTAFAEI A., KOHANDEHGHAN, A., AMIRKHIZ, B.S., SERATE, D., ZHENG, W., GUZONAS, D., CHMIELUS, M., CHEN, W., LUO, J.L., Characterization of oxide scales grown on alloy $310 \mathrm{~S}$ stainless steel after long term exposure to supercritical water at $500 \mathrm{C}$, Materials Characterization, 120, 2016 p. 273-284.

15. FULGER, M., MIHALACHE, M., OHAI, D., FULGER, S., VALECA,.S.C, Analyses of oxide films grown on AISI 304L stainless steel and Incoloy 800HT exposed to supercritical water environment, J. Nuclear Mater., 415, 2011, p. 147-157.

Manuscript received: 7.02.2020 